\title{
ACTUALIZACIÓN DIDÁCTICA DE LAS FÁBULAS: LA INTEGRACIÓN DE APRENDIZAJES LINGÜÍSTICOS Y LITERARIOS DESDE UNA PERSPECTIVA PRAGMÁTICA
}

\author{
Antonia María Ortiz Ballesteros \\ Universidad de Castilla-La Mancha
}

\begin{abstract}
RESUMEN
Desde épocas antiguas la fábula ha sido un referente de aprendizajes, variables según el momento, que han basculado desde lo puramente moral hasta lo retórico. El trabajo propone una revaloración y actualización de este género acorde a las tendencias actuales, que apuestan por integrar los aprendizajes lingüísticos y literarios desde nuevas dimensiones, a la luz de las recientes investigaciones en el terreno de la didáctica de la lengua y la literatura. Tomando como ejemplos la fábula de la zorra y el cuervo, se aboga por el empleo de este género como una herramienta eficaz para desarrollar la competencia comunicativa de los alumnos desde una vertiente pragmática que tiene en el punto de mira la oralidad, así como los usos sociales y contextualizados de la lengua.
\end{abstract}

PALABRAS CLAVE: didáctica de la lengua y la literatura - fábula - competencia comunicativa - didáctica de la oralidad - educación

\begin{abstract}
The fable has been used through the ages for diverse lessons according to the time, from the learning of rhetoric to just moral education. The present study proposes to value and to bring up to date this genre according to the present researches in Didactics in Language and Literature, that they have as objective to integrate linguistic and literary learnings. Taking as example the fable The Fox and the Crow, we propose the use of this genre as an effective tool to develop the communicative competence of the students from a pragmatic aspect, especially concerning the oral uses of the language.
\end{abstract}

KEY WORDS: didactic of languages and literature - fable - communicative competence - didactic of oral language - education

\section{INTRODUCCIÓN}

Uno de los mayores retos que actualmente tiene la educación es lograr que las enseñanzas lingüísticas y las literarias se apoyen mutuamente. En el terreno de la lengua, hoy nadie discute la necesidad de incidir en el desarrollo de la competencia comunicativa de los alumnos, sirviéndonos de las aportaciones de las Ciencias del Lenguaje y, muy específicamente, la Lingüística del texto, el Análisis del Discurso o la Pragmática lingüística. En el ámbito de la literatura, los intereses se centran en la formación de un lector competente y en el desarrollo de estrategias no solo de 
comprensión, sino de interpretación y recreación, acordes a la estética de la recepción. En esta línea, las aportaciones de los estudios sobre intertextualidad y literatura comparada permiten entrever un nuevo paradigma que sustituya el tradicional concepto de enseñar literatura por el renovado de educación literaria. Pocas veces es posible en las aulas rentabilizar de forma conjunta las contribuciones provenientes de uno y otro campo y, cuando se consigue, indudablemente adquiere gran interés desde la perspectiva didáctica.

Estudios como los de Martínez Laínez ${ }^{1}$ y Rodríguez Gonzalo ${ }^{2}$ han intentado integrar la educación lingüística y la literaria centrándose en la gramática para proponer víasdeacercamiento.RodríguezLópez-Vázquez ${ }^{3}$ sugieretextosliterarios,concretamente fábulas, para adoptar estrategias que trabajen lengua y literatura a partir de las premisas de la literatura comparada, con acciones diferentes según la potencialidad del texto. Nuestra propuesta persigue análogas metas que los investigadores citados pero se diferencia, en el caso de los primeros, en que mientras estos remiten a un paradigma formal, nos apoyaremos en otro de enfoque comunicativo, de ahí que partamos de las aportaciones de algunos de los conceptos clave de la renovación, en concreto, los vinculados a los estudios sobre la conversación, las máximas de cortesía de Leech y lo referido a la preservación de la imagen. ${ }^{4}$ Nuestro interés apunta al desarrollo de la oralidad y principalmente al diálogo y la argumentación como manifestaciones básicas en el intercambio comunicativo.

Del lado de la educación literaria, coincidimos con Rodríguez López-Vázquez en el interés por los clásicos y, dentro de estos, en la selección de las fábulas como un género privilegiado, aunque no por su interés puramente didáctico-moral, como casi siempre se ha reivindicado, ${ }^{5}$ sino por su valor estético y literario y las contribuciones que este género realiza al intertexto del alumno debido a su carácter singular, que es el que, en nuestra opinión, debe exigírsele a todo texto que se trate como literatura, tal como defienden muchos investigadores y últimamente evidencia Llorens. ${ }^{6}$ Diferimos

\footnotetext{
1 A. Martínez Laínez, C. Rodríguez Gonzalo y F. Zayas, «Textos literarios y actividades gramaticales», Textos de didáctica de la lengua y la literatura, 2 (1995), pp. 35-46.

2 C. Rodríguez Gonzalo y F. Zayas, «Sintaxis y educación literaria», Textos de Didáctica de la lengua y la literatura, 37, (2004), pp. 65-75.

3 A. Rodríguez López-Vázquez, «Estrategias didácticas en torno a la fábula», A. G. Cano Vela y C. Pérez Velarde (coords.), Canon, literatura infantil y juvenil y otras literaturas, Cuenca, UCLM-Colección Estudios, 2003, pp. 121-132.

4 Vs. especialmente M ${ }^{\mathrm{a}}$ V. Escandell, Introducción a la pragmática, Barcelona, Ariel, 1993.

5 Vs. los trabajos de A. Montaner Bueno, «Análisis del tratamiento de la fábula desde una perspectiva intercultural. Esopo y la tradición española en las aulas de $6^{\circ}$ curso de Ed. Primaria», Ensayos: Revista de la Facultad de Educación de Albacete, 28, (2013), pp. 183-195, A. Rodríguez López-Vázquez, op. cit. y A. Francia, Educar con fábulas, Madrid, CCS, 1997.

6 R. Llorens, Llorens, «Fábulas, educación literaria y didáctica de los valores: Leo Lionni», Tropelías.
} 
Actualización didáctica de las fábulas: la integración de aprendizajes lingüísticos y literarios desde una...

no obstante con Rodríguez, porque mientras que las estrategias que este propone son aplicables también a otros géneros, como puedan ser los cuentos populares, de animales, ${ }^{7}$ leyendas, etc., nuestra sugerencia se circunscribe de forma exclusiva a la fábula, al considerar las características lingüísticas que la definen y singularizan, como muestra el análisis comparado de la Fábula de la zorra y el cuervo (Conde Lucanor, cuento V) y Libro de buen amor, (estrofas 1437-1444), justificando cómo ciertos textos literarios pueden colaborar a la didáctica de los usos orales en la escuela desde una perspectiva pragmática.

\section{Tratamiento ESCOlar de las fábulas}

El uso de la fábula en la escuela está registrado desde tiempos antiguos. Es sobradamente conocida la revolución que supuso en la Edad Media el conocimiento de las fábulas de Esopo a través del Isopete y la influencia no decayó en el Renacimiento, pues los humanistas vislumbraron su potencial no solo para los aprendizajes lingüísticos sino, sobre todo, para «convencer» gracias al uso de la palabra.

M. Jesús Lacarra, a propósito de El libro de buen amor, señala la utilidad de estos textos para tareas de ampliación, reducción y cambio del punto de vista:

Estas obras se estudiaban ineludiblemente en clase y los alumnos medievales se ejercitaban con ellas para aprender las materias del trivium, siguiendo una costumbre que se había iniciado ya en el siglo II. La enseñanza medieval de la retórica tenía una vertiente práctica, en la que los escolares ampliaban, abreviaban o dramatizaban textos breves, como las fábulas. Esto explica la enorme popularidad de esta tradición y a su vez la escasa fijeza de unos textos que se guardarían en la memoria. $^{8}$

En la misma línea, C. Alvar ve en la utilidad de las fábulas para tareas escolares una de las razones de su enorme difusión:

Esta proliferación de versiones diferentes, de textos y de testimonios sólo es explicable por la popularidad de las fábulas de Esopo (y de Fedro), debido a su presencia en las escuelas como apoyo para la enseñanza de gramática y retórica en los primeros años de aprendizaje. ${ }^{9}$

Revista de Teoría de la Literatura y Literatura Comparada, 23 (2015), pp. 61-72.

7 Diferenciamos ambos siguiendo la clasificación de Thompson, muy usada en las disciplinas de Didáctica de la literatura y Literatura Infantil y Juvenil, asumida también por Teresa Colomer, en Introducción a la literatura infantil y juvenil, Madrid: Síntesis, 1999, pp. 64-65, donde se separa cuentos de animales, de fábulas.

8 M. J. Lacarra, «El libro de Buen Amor, ejemplario de fábulas a lo profano», J. Paredes y P. Gracia (eds.), Tipología de las formas narrativas breves románicas medievales, Granada, Universidad, 1998, p. 252.

9 C. Alvar, «El retrato de Esopo en los Isopetes incunables: imagen y texto», Revista de Filología Española-RFE, XCI, 2, (2011), p. 236. 
De forma análoga se expresa A. Serrano Cueto en su edición de Fernando de Arce, quien destaca varios usos. Junto a lo moral, se une siempre el aprendizaje lingüístico con fines literarios:

Es claro que esta elección respondía a una intencionalidad didáctica por parte del editor, pues se lograba así que el lector tuviera a mano no solo una compilación de fábulas prestas para la educación moral, sino también un asidero teórico con el que emprender la composición literaria. En la práctica de los progymnasmata los alumnos sometían las fábulas a todo tipo de alteraciones: las prosificaban, las ampliaban, las reducían o condensaban en un proverbio, introducían en ellas nuevos epitimios o modificaban los transmitidos, etc. Las fábulas de Arce constituyen un ejercicio de composición y ampliación en verso a partir de modelos probablemente todos en prosa. $^{10}$

Así pues, las fábulas se usaban, según se deduce, para aprender a escribir en mayor medida que para la mejora moral (aprender a ser buenos). En este sentido, los productos de los estudiantes funcionaban muchas veces como auténticos hipertextos producidos a partir del hipotexto fabulístico de referencia y las relaciones de intertextualidad se llevaban a cabo en diferente grado; dependiendo del ejercicio y las capacidades del alumno en cuestión, los resultados irían desde meros plagios hasta creaciones originales o incluso versiones, pues en ocasiones el hipotexto modificaba su género y podía darse el caso de que una narración se convirtiese en un texto dramatizado:

Las fábulas de Arce presentan alteraciones significativas respecto de los modelos antiguos, que parecen responder a diferentes prácticas de composición literaria. A primera vista lo más destacado es la extensión, que contrasta con la brevedad característica del género fabulístico. Sin duda se trata de un ejercicio de redacción escolar basado en la amplificatio, práctica habitual en las escuelas de retórica. [...] Cabe la posibilidad de que las fábulas de Arce fuesen representadas como piezas dramáticas en las aulas. ${ }^{11}$

La fábula, por tanto, es empleada en la Edad Media y en el Renacimiento tanto para la educación moral como para las enseñanzas de retórica, ${ }^{12}$ si bien la recuperación que se hizo de ella bajo las directrices ilustradas relegó la segunda de las funciones, insistiendo más en los contenidos que en la forma y prescindiendo de las recreaciones y manipulaciones que eran propias en épocas anteriores. En el siglo XVIII, los textos de Samaniego, Iriarte e incluso Hartzenbusch se convirtieron en las muestras de «alumnos aventajados» que otros habían de admirar, pero por su carácter de productos muy elaborados no dieron paso a que los estudiantes realizasen ningún tipo de ejercicio que les permitiese emular a los modelos. En España, durante la dictadura, las fábulas

10 F. de Arce, Adagios y fábulas, edición de A. Serrano Cueto, Madrid, Instituto de Estudios Humanísticos, 2002, p. LII.

11 Ibídem, p. LXV.

12 J. L. Monreal Pérez, «El uso didáctico de la fábula en la literatura renacentista alemana». Estudios humanísticos. Filología. 35, (2013), pp. 51-62. 
Actualización didáctica de las fábulas: la integración de aprendizajes lingüísticos y literarios desde una...

volvieron a tomar protagonismo con esta misma función de adoctrinamiento; en la actualidad, se ha continuado usando la fábula con algunas propuestas más o menos novedosas, de carácter interdisciplinar, ${ }^{13}$ multicultural ${ }^{14}$ o de literatura comparada ${ }^{15}$ que no recuperan la potencialidad del género cuando se vinculaba a prácticas retóricas.

\section{ANÁLISIS y CARACTERIZACIÓN DE LA FÁBUla}

De forma deliberada hemos dejado en segundo lugar la caracterización de la fábula, no solo porque se trata deungénero sobradamente conocido sino también porque creemos que lo que realmente ha dado protagonismo a la fábula radica precisamente en su uso escolar y formativo; de ahí que hayamos abordado este en primera instancia. No obstante, y por brevemente que sea, es preciso recordar qué define este tipo de texto para comprender mejor las propuestas que sobre su uso realizaremos más adelante. Dejaremos a un lado las precisiones históricas y matices que ya inició Aristóteles y nos limitaremos a lo que han aportado recientemente algunos investigadores interesados por el género desde su doble dimensión estética y didáctica.

En el ámbito disciplinar de la Didáctica de la lengua y la literatura, P. Cerrillo clasifica las obras literarias en cuatro grupos, cada uno de los cuales, según señala, correspondería a un género, y puntualiza:

Parece evidente que la Poesía es la Literatura por excelencia, y que la Didáctica, Oratoria e Historia plantean determinadas dudas acerca de su carácter literario: si las usamos como mera información, no son literatura, pero si con ellas podemos llegar a disfrutar estéticamente, sí lo son; depende, por tanto y en cierto modo, de la posición que adopte el lector ante ellas. ${ }^{16}$

Para el caso que nos ocupa, Cerrillo incluye la fábula dentro de los géneros didácticos, precisando que, «a diferencia de los géneros poéticos, en las diversas modalidades didácticas el interés estético suele ser secundario». ${ }^{17}$ La definición que se ofrece es la de «narración en prosa o en verso de una pequeña historia de la que se extrae una consecuencia moral que llamamos «moraleja»y en la que los personajes suelen ser animales». ${ }^{18}$

${ }_{13}$ M. E. Bidón Vigil de Quiñones y C. Reina Flores, «Ensayos y experiencias didácticas: Las fábulas. Una propuesta interdisciplinar». Tarbiya, 41, (2010), pp. 177-189.

14 A. Montaner, «Análisis del tratamiento de la fábula desde una perspectiva intercultural. Esopo y la tradición española en las aulas de $6^{\circ}$ curso de Ed. Primaria», Ensayos: Revista de la Facultad de Educación de Albacete, 28, (2013), pp. 183-195.

15 A. Rodríguez López-Vázquez, op. cit.

16 P. C. Cerrillo, Introducción a los estudios literarios, Cuenca, El Mirador, 1998, p. 23.

17 Ibídem, p. 28.

18 Ibídem, p. 29. 
Onieva Morales, sin embargo, incluyela fábula como una clase de cuento y la define como "Cuentos de animales -a veces también de hombres- cuya finalidad es docente, expresada en una moraleja que resume la enseñanza». ${ }^{19}$ Finalmente, Garrido incluye la fábula dentro de los géneros épicos y define las fábulas como «narraciones breves, a veces formadas por la secuencia de un único diálogo, escritas en verso o prosa. Expresa el desarrollo de un conflicto mediante relato, diálogo o ambos procedimientos a la vez». ${ }^{20}$

Así pues, las constantes que podemos atribuir a la fábula (sujetas a múltiples variaciones) desde una dimensión literaria serían su carácter narrativo, la voluntad didáctica y la presencia preferente del diálogo, además del frecuente protagonismo de los animales.

Sin embargo, si entendemos que el diálogo es la base de la comunicación oral, deberíamos contemplar también una dimensión lingüística de igual o mayor relevancia que la anterior, especialmente por cuanto el material literario llega a serlo gracias a su relación con lo lingüístico y no con lo didáctico. Pese a lo cual es infrecuente que los investigadores potencien el uso del diálogo en las fábulas como susceptible de tratamiento en las aulas y aprendizaje, frente al resto de elementos, que sí suelen abordarse de manera explícita.

Desde un punto de vista textual, las fábulas pertenecen con pocas excepciones a tipologías del texto conversacional y dialógico, aunque también las encontramos, como las que nos interesan, con carácter argumentativo. Lo que tienen en común ambos grupos es la importancia de conocer el contexto para conseguir los propósitos comunicativos. Vilá i Santasusana ${ }^{21}$ reconoce como fuentes para la enseñanza y aprendizaje del discurso oral los estudios vinculados al análisis del discurso y la lingüística del texto que señalan el texto como un ente estructurado según unas reglas en el que, además, intervienen importantes variables como la intención del emisor, las relaciones entre los participantes y los turnos de palabra. La misma autora nos señala que «la enseñanza de la lengua oral tiene sus orígenes en la Grecia antigua. La retórica clásica tenía como objeto enseñar las formas adecuadas para convencer al auditorio, para exponer las ideas con claridad y eficacia». ${ }^{22}$ Debemos recordar la recuperación que hoy se ha hecho en estos ámbitos de los estudios de retórica, incorporando la modalización, los requisitos exigidos por el principio de cooperación, las normas de cortesía y el respeto a la imagen del otro, como después veremos.

\footnotetext{
19 J. L. Onieva Morales, Introducción a los géneros literarios a través del comentario de textos, Madrid, Playor, 1992, p. 195.

20 M. A. Garrido, Nueva introducción a la teoría de la literatura, Madrid, Síntesis, 2004, p. 334.

${ }_{21}$ M. Vilá i Santasusana (coords.), El discurso oral formal, Barcelona, Graó, 2005, p. 16 y ss.

22 Ibídem, p. 17.
} 
Actualización didáctica de las fábulas: la integración de aprendizajes lingüísticos y literarios desde una...

Es de justicia recordar el trabajo de Luisa Juanatey, pionero en esta línea, que vinculaba la práctica del comentario de textos al aprendizaje lingüístico. Esta autora comparaba los textos del Isopete y el cuento de don Juan Manuel englobándolos bajo un mismo epígrafe que titulaba «Un lenguaje para convencer. La argumentación» y manifestaba explícitas relaciones de estas dos fábulas con las teorías de los actos de habla y los avances de las Ciencias del Lenguaje, al afirmar:

Como todos sabemos, para conseguir lo que quería, el zorro no ha necesitado actuar, hacer: se ha limitado a hablar. Y es que en ocasiones hablar es actuar, y esto en varios sentidos. En un sentido hacemos algo al hablar, por ejemplo, cuando prometemos. ${ }^{23}$

En la comparación que Juanatey realiza entre Esopo y don Juan Manuel, reconoce el triunfo del segundo:

Su superioridad estriba, fundamentalmente, en la habilidad de don Juan Manuel para caracterizar a un personaje a través de sus propias palabras. En su apólogo el raposo se retrata a sí mismo como un habilísimo engañador, que va llevando al cuervo poco a poco a convencerse de que es extraordinario entre las aves y, en consecuencia, poniéndole en un estado de entontecimiento, de vulnerabilidad producida por la sucesión de halagos creíbles. Pues este personaje no miente de forma inmediata ni con descaro, como hace el zorro del Isopete, sino a base de medias verdades, de establecer comparaciones con lo que más conviene, y de aplicar argumentos comúnmente aceptados, que no inspiran sospecha ni duda. ${ }^{24}$

Compartimos totalmente la opinión de esta autora al interpretar que la fábula en Juan Manuel «ejemplifica el poder de la palabra como instrumento de dominio» ${ }^{25}$ y solo de forma secundaria «enseña cuánto vale el ingenio, siempre el saber prevalece sobre la fuerza». ${ }^{26}$ Desde nuestra posición de estudiosos del lenguaje sabemos que las palabras ordenan el pensamiento y que las buenas ideas solo lo son cuando toman una forma verbal adecuada. Así pues, la recepción de las fábulas que tratamos debe dirigirse, como ahora propondremos, no a interpretar que los personajes consiguen sus propósitos exclusivamente porque son «más listos» sino porque son capaces de usar con mayor eficacia un instrumento que los convierte en astutos: el lenguaje.

\subsection{Las fábulas como textos orales formales}

En primera instancia, tendríamos que partir de considerar las fábulas como textos orales propios del registro formal, reconociendo los rasgos que le son inherentes.

\footnotetext{
23 L. Juanatey, Aproximación a los textos narrativos en el aula (II). Práctica del comentario y aprendizaje lingüístico, Madrid, Arco-Libros, 1998, pp. 79-80.

24 Ibídem, pp. 80-81.

25 Ibídem, p. 79.

26 A. Rodríguez López-Vázquez, op. cit., p. 122.
} 
Esto justificaría sobradamente su uso escolar, pues como la lengua oral formal precisa siempre de aprendizaje, las fábulas resultan útiles, debido a que su sencillez facilita la aceptación por parte de los estudiantes.

La formalidad se evidencia en algunas de sus características, que no siempre se explicitan y pueden pasar inadvertidas. La primera es que se trata de una comunicación relativamente unidireccional en la que solo uno de los interlocutores es protagonista preferente de la conversación, si bien sus fines se centran en el otro. Excepcionalmente, la palabra se otorga a un único personaje: vemos que la raposa es la única que toma la palabra en el cuento v del Conde Lucanor, la fábula de La zorra y el cuervo, y no parece que tener un queso sea impedimento, pues el ave finalmente lo olvida. Más bien cabe pensar que el cuervo prefiere escuchar en lugar de hablar porque lo que recibe son halagos y el silencio le permite disfrutar de ellos. Mientras los halagos son escasos, el cuervo retiene el queso como garantía para conseguir más, pero cuando estos logran sus efectos, lo emocional prevalece sobre lo puramente físico -la comida- y no le importa perder el queso. También está presente el rasgo de planificación, propio de la lengua oral formal, lo que justifica el uso de recursos literarios al tiempo que garantiza la eficacia de estos.

Una lectura superficial del relato podría llevarnos a pensar que la capacidad de la zorra para conseguir su objetivo gracias al diálogo es innata (fruto de su astucia e inteligencia), espontánea por tanto, pero una lectura atenta, desde la perspectiva actual, permite deducir que la maestría del animal no se debe a pura inventio, a una inspiración feliz, sino más bien a un trabajo previo de planificación que incluye la estrategia, elaboración y reflexión sobre sus posibilidades considerando el conocimiento del interlocutor y del contexto. La zorra no hace sino emular, a modo de imitatio, las técnicas más conocidas de los mejores oradores y retóricos clásicos. A la antigua Grecia se remontan las colecciones más conocidas de fábulas, que Aristóteles no reconocía como género ficticio independiente sino una de las numerosas formas del orador para conseguir la persuasión o, lo que es lo mismo, similar a una figura retórica. Además, la raposa parece adelantarse en el tiempo al principio de cooperación de Grice ${ }^{27}$, mostrando que, como el cuervo, conoce la máxima de calidad, pues para que la conversación avance es preciso suponer que el interlocutor no miente ${ }^{28}$ o de lo contrario el diálogo carecería de sentido; así se explica la confianza del ave.

Esta misma certidumbre, base del diálogo, funciona también en otros relatos del Conde Lucanor, como el cuento 12 «La zorra y el gallo», el 19 «Los cuervos y los

\footnotetext{
27 H. P. Grice, «Lógica y conversación», en L. M. Valdés, La búsqueda del significado, Madrid, Tecnos-UM, 1991, pp. 511-530.

28 La máxima de calidad de Grice insta a que la contribución sea verdadera e incluye dos submáximas, no decir aquello que considera falso ni aquello sobre lo que no se tienen pruebas.
} 
Actualización didáctica de las fábulas: la integración de aprendizajes lingüísticos y literarios desde una...

búhos» o el 22 «El león y el toro», en los que las consecuencias devienen de fiarse de que efectivamente, las palabras no solo dicen sino que hacen. ${ }^{29}$

Además del principio de cooperación, es posible encontrar en estas fábulas claros ejemplos de cómo funciona la cortesía lingüística ${ }^{30}$. Recordemos que la finalidad de las estrategias que se desarrollan es mantener un equilibrio social, establecer relaciones cordiales y minimizar el conflicto que puede producir no solo la diferencia jerárquica entre los interlocutores sino la distancia entre las intenciones de uno y otro en relación al objetivo final perseguido.

Una de las máximas de la cortesía es la valoración del interlocutor. Esta alcanza unos límites ponderativos en boca de los emisores-zorro que permiten poner en duda la sinceridad de sus palabras, bien por los significados co-textuales bien por los puramente pragmáticos, haciendo peligrar el logro del propósito comunicativo. Así sucede tanto en el caso de Juan Ruiz como de don Juan Manuel pero particularmente en el primero. Gracias a que las historias están contextualizadas en otra estructura superior son los «mediadores» los que interpretan la fábula a partir de sus propios conocimientos con la intención de garantizar que la comprensión sea la adecuada. Sin embargo, en el segundo caso, la monja doña Garoça sustenta su incredulidad en dos razones vinculadas al conocimiento del mundo y los saberes compartidos. ${ }^{31}$ Sin embargo, la raposa de don Juan Manuel no dice mentiras sino verdades a medias (respeta la máxima de Grice) y reconoce a su interlocutor algunos méritos, que son precisamente los que usa. Seguramente por eso la zorra de El conde Lucanor consigue sus propósitos y la de El libro de buen amor (en su alter-ego) los yerra.

\subsection{La fábula como texto oral argumentativo}

Además de las normas que rigen el diálogo, se deducen otros aprendizajes pragmáticos. Dentro del discurso retórico, la argumentación es una pieza destacada

\footnotetext{
29 El error no reside en dejarse guiar por la máxima de calidad que, como se deduce, es condición inexcusable para que el diálogo avance, sino en hacerlo de manera exclusiva, desatendiendo otras informaciones derivadas del contexto (el emisor, las intenciones, etc.). De forma explícita lo señala don Juan Manuel en el cuento 22: «Por eso creo que si vuestro amigo es hombre leal y hallasteis en él siempre buenas obras [...], no debéis oír nada de lo que os digan en contra suya, antes os aconsejo que le informéis de ello, para que él a su vez os informe de lo que le digan en contra vuestra».

30 Para esta cuestión, además de las conocidas máximas de Leech, es un referente el trabajo de M. Victoria Escandell, «Cortesía, fórmulas convencionales y estrategias indirectas», Revista Española de Lingüística, 25, (1995), pp. 31-66.

31 En primer lugar, que las monjas no pueden pecar, aun suponiendo que los intereses fueran sinceros, es decir, que se respetase la máxima de calidad; en segundo, que existe evidencia de que los intereses no son sinceros (se ha atentado por tanto contra la máxima), porque el conocimiento de los hombres (información extratextual) permite afirmar que sus intereses son otros.
} 
cuya finalidad consiste en persuadir al destinatario con pruebas que, en ocasiones, incluyen la refutación de las tesis contrarias. Para Plantin, argumentar «es intentar transformar por medios lingüísticos el sistema de creencias y de representaciones del interlocutor» ${ }^{32}$; y esto es, con certeza, lo que hacen los protagonistas de las fábulas seleccionadas, bien que con diferente fortuna. Es relevante la afirmación de Cros cuando indica que «a diferencia de los razonamientos formales y de la demostración, no parte de lo que es cierto o falso, sino de lo que puede resultar más o menos verosímil $»^{33}$ en relación al sistema de valores de un destinatario único o de una comunidad. En los casos que nos ocupan, la cuestión de la verdad o falsedad de los argumentos de la zorra no es lo esencial pero la verosimilitud sí queda garantizada cuando acudimos a conocimientos contextuales. ${ }^{34}$ Gracias a la transmisión la imagen positiva que consigue la zorra con los halagos (máxima de simpatía), el cuervo responde (en un intercambio de cortesía) de la misma manera y no ve a la zorra como una falsa, sino como una amiga. Estamos de nuevo ante la aplicación del principio de cortesía con las máximas que Leech formuló. Los argumentos de la zorra, que desde la posición del lector externo son completamente absurdos, se tornan verosímiles y por eso son eficaces, porque tienen, en función del auditorio al que se dirigen, un alto grado de aceptabilidad; el conocimiento del cuervo que tiene la zorra permite a esta emplearlos, a sabiendas de que el ave los dará como válidos.

Por lo demás, el resto de requisitos del discurso argumentativo, expuestos también por Cros y Vilà ${ }^{35}$ en sus propuestas de secuencias didácticas, son aplicables a lo que venimos diciendo. En la Fábula de la zorra y el cuervo se ejemplifican todas estas cuestiones. La planificación incluye tres partes: el saludo, el halago y la instancia al canto. Las previsiones sobre el destinatario suponen el conocimiento de la excesiva vanidad y la torpeza del cuervo en el caso de Juan Ruiz y la necesidad de reafirmación de la imagen personal, en parte dañada por la carencia de méritos, en el caso de don Juan Manuel. Los argumentos en ambos casos son los mismos y también el orden en que aparecen: los primeros, tendentes a reforzar las dos cualidades físicas que los pájaros poseen: la belleza (como el pavo real, como la garza, como el cisne...) y el

32 Apud A. Cros, «La argumentación oral», en M. Vilà y Santasusana (coord.), El discurso oral formal, Barcelona, Graó, 2005, p. 58.

33 Ibídem, p. 59.

34 Especialmente por la obnubilación de los sentidos (y preferentemente del «sentido común») que se presupone ante la muestra de palabras (interpretadas como acciones) que nos hacen sentir queridos, apreciados, valorados. Si las palabras de la zorra no consiguiesen esa sensación sería imposible que el ave creyese como verdaderas las cualidades que indica, a todas luces exageradas. Lo que se está produciendo aquí es la falsa percepción, por parte del cuervo, de que la zorra ve en él virtudes que a otros les están vedadas y que él reconoce como propias, la vieja máxima de que «el amor es ciego».

35 A. Cros y M. Vilà i Santasusana, «La defensa de un punto de vista», en M. Vilà y Santasusana (coord.), El discurso oral formal, Barcelona, Graó, 2005, pp. 151-161. 
Actualización didáctica de las fábulas: la integración de aprendizajes lingüísticos y literarios desde una...

canto (como el ruiseñor, el tordo...); los segundos, vinculados a cualidades morales: el canto produce placer o complacencia - en cualquier caso beneficio-, al que escucha. La verosimilitud se explica por el deseo del cuervo de verse amado pero también reconocido entre el resto de aves. Sin embargo, la prueba de dicho reconocimiento no debe ser muestra de vanagloria (éticamente inaceptable) sino moralmente deseable por los efectos positivos que causa en el otro. La zorra también lo sabe y lo hace explícito.

Finalmente, cabe advertir que, como las fábulas se presentan con los rasgos de la lengua oral formal, el interlocutor no puede rebatir con contraargumentos porque el texto se presenta como si tuviese carácter escrito y diferido. Paradójicamente, el interlocutor permanece impasible ante los argumentos del emisor hasta que, finalmente, sucumbe a ellos, lo que permite que el lector (destinatario del texto literario) asuma, siquiera parcialmente, una posición activa, anticipando sucesos, previendo consecuencias, recelando del emisor y, en definitiva, convirtiéndose en el auténtico receptor del texto que se propone. El componente literario en este proceso resulta imprescindible o el efecto didáctico ni se produciría ni tendría sentido. El lector necesariamente debe identificarse con uno de los dos interlocutores, bien que a modo de alter ego para preservar su imagen. El receptor puede concluir la lectura admirando a la zorra, despreciando al cuervo o incluso compadeciéndose pero, en cualquier caso, ha comprendido el texto, lo ha interpretado y se ha convertido en lector activo.

\section{Conclusiones}

Tras lo expuesto, podemos concluir que, sin renunciar al innegable carácter didáctico de la fábula, el tratamiento de esta debe ser actualizado, porque también el uso de los textos tradicionalmente empleados con valor educativo debe adaptarse a las necesidades del momento. Por eso la fábula ha variado en su uso desde la Edad Media hasta la actualidad, y hoy sería inadmisible seguir empleando este género, tan rico literariamente, en usos que satisfacían demandas de otros momentos. Según se ha demostrado, puede adaptarse sin dificultad alguna a las exigencias actuales de las enseñanzas tanto lingüísticas como literarias, integrando ambas de forma modélica.

Por lo que respecta al uso que se le da hoy, como señala Llorens «Que ética y estética convivan no quiere decir que la literatura esté obligada a transmitir valores sociales». ${ }^{36}$ Aunque podamos reconocer a la fábula la capacidad de «educar en valores», que actualmente quiere atribuirse como cualidad principal (y a veces única) de la literatura infantil y juvenil, la realidad es que hacerlo negaría lo que esencialmente es: un constructo lingüístico con características definidas, que responden a una finalidad

36 R. Llorens, op. cit., p. 61. 
comunicativa, pero también un objeto estético, con valores singulares que es preciso reivindicar. Esta ha sido por tanto nuestra propuesta: actualizar el uso que se da a las fábulas para que, como ha sido desde su nacimiento, siga aportando a los lectores de todas las épocas y edades disfrute, placer, entretenimiento, reflexiones y, como no puede ser menos, el aprendizaje que se deriva de todo ello.

\section{Bibliografía}

Alvar, C., «El retrato de Esopo en los Isopetes incunables: imagen y texto», Revista de Filología Española-RFE, XCI, 2, (2011), pp. 233-260.

Arce, F. de, Adagios y fábulas, edición de A. Serrano Cueto, Madrid, Instituto de Estudios Humanísticos, 2002.

Bidón VigIl de QuiÑones, M. E. y Reina Flores, C., «Ensayos y experiencias didácticas: Las fábulas. Una propuesta interdisciplinar», Tarbiya, 41, (2010), pp. 177-189.

Cerrillo Torremocha, P. C., Introducción a los estudios literarios, Cuenca, El Mirador, 1998.

ESCANDELL, M. V. (1995). «Cortesía, fórmulas convencionales y estrategias indirectas», Revista Española de Lingüística, 25, (1995), pp. 31-66.

EsCANDELl, M. V., Introducción a la pragmática, Barcelona, Ariel, 1993.

GARRIDO, M. A., Nueva introducción a la teoría de la literatura, Madrid, Síntesis, 2004.

JuAnatey, L., A proximación a los textos narrativos en el aula (II). Práctica del comentario y aprendizaje lingüístico, Madrid, Arco-Libros, 1998.

Grice, H. P., «Lógica y conversación», en L. M. Valdés, La búsqueda del significado, Madrid, Tecnos-UM, 1991, pp. 511-530.

LACARra, M. J., «El libro de Buen Amor, ejemplario de fábulas a lo profano», en J. Paredes y P. Gracia (eds.), Tipología de las formas narrativas breves románicas medievales, Granada, Universidad, 1998, pp. 237-252. Disponible en http:// www.cervantesvirtual.com/obra-visor/el-libro-del-buen-amor-ejemplario-de-fabulasa-lo-profano/html/ec37eb0d-5d04-4b6f-bf11-ef6d26cc9fbb_4.html [Consultado 0810-15].

Martínez Laínez, C., Rodríguez Gonzalo, C. y Zayas, F., «Textos literarios y actividades gramaticales», Textos de didáctica de la lengua y la literatura, 2 (1995), pp. 35-46.

Monreal PÉrez, J. L., «El uso didáctico de la fábula en la literatura renacentista alemana». Estudios humanísticos. Filología. 35, (2013), pp. 51-62.

MONTANER, A., «Análisis del tratamiento de la fábula desde una perspectiva intercultural. Esopo y la tradición española en las aulas de $6^{\circ}$ curso de Ed. Primaria», Ensayos: Revista de la Facultad de Educación de Albacete, 28, (2013), pp. 183-195. 
Actualización didáctica de las fábulas: la integración de aprendizajes lingüísticos y literarios desde una...

Onieva Morales, J. L., Introducción a los géneros literarios a través del comentario de textos, Madrid, Playor, 1992.

Rodríguez Gonzalo, C. y Zayas, F., «Sintaxis y educación literaria», Textos de Didáctica de la lengua y la literatura, 37, (2004), pp. 65-75.

Rodríguez López-VÁzquez, A., «Estrategias didácticas en torno a la fábula», en A. G. Cano Vela y C. Pérez Velarde (coords.), Canon, literatura infantil y juvenil y otras literaturas, Cuenca, UCLM-Colección Estudios, 2003, pp. 121-132.

VilÁ I Santasusana, M. (coord.), El discurso oral formal, Barcelona, Graó, 2005. 